\title{
A TRADUÇÃO DA SUBJETIVIDADE NAS DUAS VERSÕES FRANCESAS DE GRANDE SERTÃO: VEREDAS
}

Márcia Valéria Martinez de Aguiar*

Resumo: Grande sertão: veredas foi vertido pela primeira vez para o francês em meados dos anos 1960, recebendo uma segunda tradução para essa língua no início dos anos 1990. Retraçar o projeto tradutório que guiou cada um desses trabalhos, buscando identificar como cada tradutor entendeu a singularidade da escrita de Guimarães Rosa, é o objetivo deste artigo.

Palavras-chave: Tradução. Subjetividade. Grande sertão: veredas.

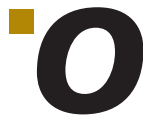

s tradutores que, ao longo dos anos 1960, se corresponderam com Guimarães Rosa no momento mesmo em que vertiam para francês, inglês, alemão, italiano e espanhol obras como Corpo de baile, Grande sertão: veredas, Sagarana e Primeiras estórias não escondem o fascínio e a rudeza da tarefa. Mergulhado "até o pescoço" em Primeiras estórias, Jean-Jacques Villard comenta que há momentos em que ele "arrancaria os cabelos" se não se retivesse "por prudência estética" (Jean-Jacques Villard a Guimarães Rosa, 25.3.1967 in ROSA, [1961-1967]) ${ }^{1}$. Edoardo Bizzarri, ao enfrentar Corpo de baile, tem a impressão de atravessar um Rubicão, mas, ao contrário do riachinho "mais pedras do que água, transponivel sem molhar os pés, como aquele que originou a metáfora”, o seu Rubicão é "um verdadeiro São Francisco, enorme, com águas profundas, as margens que se perdem no horizonte", e nele ele entrará "numa canoa furada" (Edoardo Bizzarri a Guimarães Rosa, 20.5.1963 in ROSA, 1981, p. 16-17). Harriet de Onís, no esforço de traduzir Sagarana, identifica-se, na fórmula de despedida de sua carta de 31.1.1964 a Guimarães Rosa, como "sua miúda, resignada e teimosa burrinha pedrês" (apud VERLANGIERI, 1993, p. 208). Ángel Crespo, ao se debruçar sobre Grande 
sertão: veredas, sente-se "muito contente e muito assustado, pois traduzir o seu extraordinário livro é um trabalho que vai por a prova todos os meus recursos de brasilianista, poeta e pai de família" (Ángel Crespo a Guimarães Rosa, 2.12.1964 in ROSA, [1964-1967]).

O desafio consiste em formular em outras linguas textos que, firmemente ancorados na terra natal de Guimarães Rosa, o sertão, se alçam ao universal. Essa ligação com o sertão manifesta-se de muitas maneiras: abundância de nomes de plantas, animais, localidades, presença maciça das paisagens geográficas, das realidades econômicas e sociais, das personagens, dos costumes, do imaginário e dos falares da região. Contudo, como assinalaram desde sempre os críticos, o traço característico da obra rosiana consiste em eludir toda leitura realista.

Como "feiticeiro da palavra", Guimarães Rosa burla a matéria estritamente geográfica, histórica, linguística, com ela construindo textos em que as distinções entre imaginário e concreto, metafísico e físico, forma e conteúdo, subjetivo e objetivo se tornam insensatas. Remetendo-se a Goethe, o escritor define o sertão como "o terreno da eternidade, da solidão, onde Inneres und Ausseres sind nicht zu trennen [o interior e o exterior já não podem ser separados]" (ROSA, 1983, p. 86). O homem que habita o sertão é uma unidade originária, "um eu que ainda não encontrou um tu", a palavra absoluta que cria o mundo, que está "além do céu e do inferno" (ROSA, 1983, p. 86). Para o demiurgo e para o poeta o corpo vivo do ser são as palavras em sua materialidade gráfica e sonora, em seus sentidos referenciais, figurados, correntes, raros ou recriados pelo escritor no tecido de sua escrita.

Todas as camadas da trama urdida por Guimarães Rosa são atravessadas pela fusão entre interno e externo. Essa unidade se apresenta de múltiplas maneiras e de modo singular em cada um de seus textos. Nosso objetivo sendo, neste artigo, examinar as duas traduções de Grande sertão: veredas publicadas na França, apontaremos brevemente como esse entrelaçamento se faz nessa obra, apoiando-nos em estudos críticos e nos comentários do próprio escritor em sua correspondência com seus tradutores.

Grande sertão: veredas dá voz a Riobaldo Tatarana, ex-jagunço tornado fazendeiro que conta a um jovem doutor vindo da cidade suas antigas aventuras, buscando ressignificá-las a partir das angústias que essas vivências nele deixaram: o diabo existe ou não existe, o bem e o mal podem ser separados, como entender o mistério de Diadorim? Esse relato, feito em primeira pessoa, não se confunde, porém, com uma simples rememoração de acontecimentos e pensamentos que estariam separados do narrador. Ao contrário, tanto a realidade fisica - o sertão - quanto a subjetividade de Riobaldo são tecidas no desenrolar da narrativa.

Já no primeiro parágrafo, os elementos geográficos, os topônimos, as superstições e o imaginário da região são dispostos de tal modo que ao sertão "real" se sobrepõe um sertão mítico que, longe de ser delimitado, "está em toda parte" (UTÉZA, 2016, p. 36-42). No decorrer do romance, uma mesma paisagem se metamorfoseia conforme a situação e o estado de ânimo do sujeito que entra em contato com ela. Assim, o Liso do Sussuarão mostra-se inóspito para Medeiro Vaz e acolhedor para Riobaldo Tatarana, de modo que não é mais a terra que molda o homem, mas o homem que passa a moldar a terra. É Antonio Candido (1983, p. 298-299) que explica: 
A variação da paisagem, inóspita e repelente num caso, sofrível no outro, foi devida ao princípio de adesão do mundo físico ao estado moral do homem, que é uma das partes da visão elaborada neste livro: "[...] sertão é onde o pensamento da gente se forma mais forte que o poder do lugar." "Sertão não é malino nem caridoso, mano oh mano! - ...ele tira ou dá, ou agrada ou amarga, ao senhor, conforme o senhor mesmo".

As palavras não se colocam como mera representação de uma realidade externa, mas passam a constituir essa realidade, que se subjetiviza. Mas o próprio Riobaldo Tatarana não é exterior ao que narra, como se verifica nesta passagem, desvendada pelo escritor ao tradutor alemão Curt Meyer-Clason, ao comentar com ele alguns trechos da tradução americana do romance: "O que lembro, tenho. Venho vindo, de velhas alegrias” (ROSA, 2006, p. 188).

Nessa fala de Riobaldo a seu interlocutor, Guimarães Rosa coloca em primeiro lugar o predicado, separando-o do verbo e do sujeito oculto por uma vírgula. Com essa inversão, ele destaca o "ter", a posse do vivido pelo ato de contar, afasta-se do lugar comum dos velhos e faz com que o sujeito se constitua na fala. Nas palavras do escritor:

Riobaldo quer dizer que a memória é para ele uma posse do que ele viveu, confere-lhe propriedade sobre as vivências passadas, sobre as coisas vividas. Toda uma estrada metafísica pode ter ponto-de-partida nessa concepção. E o que os tradutores entenderam, chatamente, trivialmente, foi que Riobaldo, empobrecido, em espírito, pela vida, só possuísse agora, de seu, suas lembranças. Um lugar-comum dos velhos. Justamente o contrário (Carta a Curt Meyer-Clason, 17.6.1963 in ROSA, 2003, p. 114).

A subjetivização da escrita em Guimarães Rosa está intimamente ligada ao modo peculiar como ele maneja o português falado no Brasil, especialmente no sertão. Muitos estudiosos já se referiram à autenticidade dessa língua sertaneja, apontando também, ao mesmo tempo, o modo como Guimarães Rosa cria, com ela, uma poética singular (PROENÇA, 1958; WARD, 1984). O depoimento de Manuel Bandeira, em carta ao escritor, resume esse procedimento:

Ao despois de depois, andaram dizendo que você tinha inventado uma língua nova e eu não gosto de língua inventada. Sempre arreneguei de esperantos $e$ volapuques. Vai-se ver, não é língua nova nenhuma a do Riobaldo. Difícil é, às vezes. Quanta palavra do sertão!

[...]

Ainda por cima disso, você fez Riobaldo poeta, como Shakespeare fez Macbeth poeta. Natural: por que um jagunço dos gerais demais do Urucuia não poderá ser poeta? Pode sim. Riobaldo é você se você fosse jagunço. A sua invenção é essa: pôr o jagunço poeta inventando dentro da linguagem habitual dele (Carta de Manuel Bandeira a Guimarães Rosa, 13.3.1957 in BANDEIRA, 1967, p. 591).

Graças a esse manejo, as formulações aparentemente mais corriqueiras escondem sentidos que são apreendidos quando se atenta ao modo como elas integram a totalidade do texto. A disposição das palavras nas frases, nos parágra- 
fos, no livro cria o sentido, de modo que o semântico não pode ser separado da forma que o expressa. O que fez com que Augusto de Campos (1970, p. 41) equiparasse Guimarães Rosa a Joyce e a Mallarmé: "Os grandes conteúdos do Grande sertão", diz ele, "como os de Joyce, se resolvem não só através da, mas na linguagem". Na escrita de Guimarães Rosa nada é arbitrário: deslocamentos sintáticos, seleção lexical, assimilação da fala sertaneja, recorrências fônicas, para só citar alguns dos múltiplos recursos usados pelo escritor, não são formas vazias que simplesmente "vestem" um conteúdo exterior a elas. Constituem, ao contrário, o próprio sentido, criam a unidade de interno e externo, sujeito e objeto. Apreender o modo como as traduções recriaram essa singularidade da escrita de João Guimarães Rosa será o fio condutor de nossa análise.

Embora sem explicitá-los, tomamos como base o conceito de significância, elaborado por Mário Laranjeira (1993), na esteira de Michel Riffaterre e Julia Kristeva, a noção de ritmo, elaborada por Henri Meschonnic (1982) e a de letra, desenvolvida por Antoine Berman (2007), que parecem apontar, por diferentes caminhos, que o importante a resgatar em uma tradução literária é a poética que singulariza uma obra.

\section{As TRADUÇÕes}

Realizada por Jean-Jacques Villard, a primeira tradução de Grande sertão: veredas foi publicada em 1965, recebendo o nome de Diadorim. Quase 30 anos depois, em 1991, o romance foi relançado, com o mesmo título, na versão de Maryvonne Lapouge-Pettorelli ${ }^{2}$. Para caracterizar uma e outra selecionamos uma pequena passagem, que analisaremos da perspectiva dos tempos verbais:

Mas daí voltamos, desatravessando outra vez o Soninho, até onde estava a nossa mulada com munição e o mais. Mesmo viemos negaceando de recuar. Assim era pena, mas carecíamos de flautear desse jeito, sustância nossa não dava para se acabar com aqueles judas de uma vez. Sempre, sempre, para enganar no que vissem, Zé Bebelo variava de se viajar uma hora quase todos juntos, outra hora despedidos espalhados. Ainda, por suma vantagem disso, demos um tiroteio ganho, na fazenda São Serafim, dos diabos!

Rumo a rumo de lá, mas muito para baixo, é um lugar. Tem uma encruzilhada. Estradas vão para as Veredas Tortas - veredas mortas. Eu disse, o senhor não ouviu. Nem torne a falar nesse nome, não. É o que ao senhor lhe peço. Lugar não onde. Lugares assim são simples - dão nenhum aviso. Agora: quando passei por lá, minha mãe não tinha rezado - por mim naquele momento? (ROSA, 2006, p. 97) ${ }^{3}$.

2 Existe uma terceira tradução, ainda inédita, finalizada em 2014 por Francis Utéza, que não comentaremos em nosso artigo. A respeito dela, contudo, pode-se consultar a entrevista que ele nos concedeu a esse respeito "A metafísica roseana em tradução" (UTÉZA, 2015), que, em breve, será republicada na coletânea Infinitamente Rosa, organizada pelas professoras Sandra Vasconcelos, Cleusa Rios Passos e Yudith Rosenbaum. Fruto do evento "Infinitamente Rosa" realizado pelo Instituto Brasileiro e pela Faculdade de Filosofia, Letras e Ciências Humanas da Universidade de São Paulo, de 13 a 15 de setembro de 2016 , essa coletânea trará também um artigo de Francis Utéza em que ele comenta o seu trabalho, Grande sertão: veredas - o redemundo da tradução francesa.

3 As páginas do original e das traduções correspondem às das edições citadas nas Referências. Para o caso das edições francesas, além das edições referidas, indicaremos as versões de Jean-Jacques Villard e de Maryvonne Lapouge-Pettorelli usando as abreviações JJV e MLP. 
Nous, on s'en est retourné, traversant encore le Soninho, jusqu'à l'endroit où étaient les mules, avec les munitions et le reste. On y est même allé en faisant mine de se replier, pour les attirer. Ça faisait chagrin, mais fallait bien ruser avec ces judas, on était pas de force pour en finir d'un coup avec eux. Pour les tromper sur ce qu'ils voyaient, Zé Bebelo nous faisait tout le temps changer, tout le temps: un moment on voyageait tous ensemble, celui d'après on chevauchait dispersés. On en a ainsi profité pour lâcher une sacrée fusillade sur la fazenda São Serafim.

De ce côté, mais bien plus bas, y a un endroit. Un carrefour. Les chemins mènent aux Veredas Tortas, Combes Tortes... combes mortes. Je l'ai dit; faut pas que Monsieur l'ait entendu. Et qu'il aille parler de ce nom. Je le demande à Monsieur. Un endroit nulle part. Les endroits comme ça sont ordinaires... ils vous préviennent pas. Mais quand je suis passé par celui-là, ma mère avait pas prié pour moi,... à ce moment (ROSA, 1965, p. 75 - JJV).

Puis nous fîmes demi-tour, en retraversant l'Ensommeillée là où se trouvait notre petite escouade de mules, avec les munitions et le reste. On se repliait sans battre en retraite. C'était dommage, mais nous étions obligés de frimer ainsi, nos effectifs ne suffisaient pas pour en finir une fois pour toutes avec ces Judas. Constamment, constamment pour les tromper sur ce qu'ils verraient, Zé Bebelo changeait notre façon de voyager, à un moment presque tous ensemble, à un autre dispersés, éparpillés. De plus, autre avantage suprême de cette tactique, nous ouvrîmes un feu de tous les diables, dans la fazenda Saint-Séraphin, avec succès.

Continuant dans cette direction, mais beaucoup plus bas, il y a un endroit. C'est une croisée de chemins. Les routes mènent à Veredas Tortes, moitié mares, moitié marigots: des veredas mortes. J'ai dit, vous n'avez pas entendu. N'allez plus jamais prononcer ce nom. C'est ce dont je vous prie. Un endroit de nulle part. Les endroits de ce genre sont quelconques - ils ne préviennent pas. Maintenant: quand je suis passé par là, ma mère ce jour-là-n'avait donc pas prié pour moi? (ROSA, 1991, p. 113 - MLP).

$\mathrm{Na}$ lingua francesa, existem duas formas que correspondem ao pretérito perfeito do português: o passé composé e o passé simple. Jean-Jacques Villard escolheu o passé composé para constituir a fala de Riobaldo. Maryvonne Lapouge-Pettorelli usa o passé composé nos momentos em que o narrador interpela ou dirige algum comentário a seu interlocutor, optando pelo passé simple quando esse mesmo narrador passa a contar algum episódio de seu passado.

Conforme a teoria da enunciação desenvolvida por Émile Benveniste (1995), o uso do passé simple e do passé composé distingue dois planos de enunciação, o plano da enunciação da história e o plano da enunciação do discurso. A escolha de Jean-Jacques Villard pelo passé composé faz com que a narrativa de Riobaldo se desenvolva, tanto nos momentos em que interpela o seu interlocutor quanto nos momentos em que narra episódios de seu passado, no plano da enunciação do discurso. Maryvonne Lapouge-Pettorelli, que segmenta a fala de Riobaldo em dois momentos, faz com que os episódios de sua vida de jagunço se desenrolem no plano da enunciação da história. Isso faz com que o leitor francês 
insira esse romance, conforme leia a versão de Villard ou de Lapouge-Pettorelli, em dois universos literários diferentes.

O passé simple é um elemento fundamental da escrita dos romances do século XIX, enquanto o passé composé será incorporado à literatura, de forma mais generalizada, a partir do século XX, quando diferentes escritores como Charles-Ferdinand Ramuz, Jean Giono, Louis-Ferdinand Céline, Raymond Queneau, entre muitos outros, reivindicarão o uso da língua falada como maneira de libertar a escrita literária da língua acadêmica que tinha acabado por ossificá-la. A filiação a um ou a outro desses universos muda radicalmente a feição que a narrativa de Grande sertão: veredas adquirirá em língua francesa no que diz respeito à ligação entre interno e externo, subjetividade e objetividade.

Roland Barthes (2004) em seu artigo "A escrita do romance" esclarece a função que passé simple e passé composé desempenham na escrita literária. Mais do que exprimir uma temporalidade o passé simple, diz ele, "funciona como o sinal algébrico de uma intenção", indicando que todos os acontecimentos estão entrelaçados logicamente com vistas a certo fim:

Seu papel é reduzir a realidade a um ponto, e abstrair da multiplicidade dos tempos vividos e superpostos um ato verbal puro, desvencilhado das raízes existenciais da experiência e orientado para uma ligação lógica com outras ações, outros processos, um movimento geral do mundo: ele visa a manter uma hierarquia no império dos fatos (BARTHES, 2004, p. 28).

Esse entrelaçamento lógico dos acontecimentos só pode ser feito por um narrador que observe o movimento das personagens de um ponto de vista externo, sabendo de antemão que as ações delas desembocarão em uma finalidade estabelecida desde o princípio. Por essa razão, Barthes (2004, p. 29) compara o narrador a um demiurgo:

Por trás do "passé simple" esconde-se sempre um demiurgo, deus ou recitante; o mundo não é inexplicado quando se recita, cada um de seus acidentes é apenas circunstancial, e o "passé simple" é precisamente esse signo operacional pelo qual o narrador reduz a explosão da realidade a um verbo tênue $e$ puro, sem densidade, sem volume, sem desdobramentos, cuja única função é unir o mais rapidamente possível uma causa e um fim.

O uso do passé simple indica, assim, a separação entre sujeito e objeto. O sujeito que conta uma história é um simples observador de seu desenrolar, aquele que, na metáfora de Stendhal (1979, p. 341-342), “carrega nas costas o espelho" que, levado por uma estrada, refletirá a realidade, seja ela bela - "o azul dos céus" - ou feia - "a lama da estrada".

O passé composé, ao contrário, rompe com a ordenação dos acontecimentos com uma finalidade. Eles apresentam-se superpostos, sem significados definidos. O narrador não se coloca mais como o observador de um objeto que lhe é exterior, mas como um sujeito que, em última instância, irá se constituir, na escrita, como o seu próprio objeto. Isso não significa que esses textos se abstenham de qualquer referencialidade. Mas ela será inseparável do sujeito que a constrói e se constrói no texto: 
[...] quando no interior da narração o "passé simple" é substituído por formas menos ornamentais, mais frescas, mais densas e mais próximas da fala (o presente ou o "passé composé"), a Literatura se torna depositária da espessura da existência, e não de sua significação. Separados da História, os atos não ficam mais separados das pessoas (BARTHES, 2004, p. 30).

Ao usar o passé composé para dar voz a seu Riobaldo Tatarana, Jean-Jacques Villard possibilita que esse narrador não se separe dos acontecimentos que relata. Tanto ao dirigir-se diretamente a seu interlocutor como ao contar a sua história, Riobaldo se coloca como pessoa, no sentido que Benveniste confere a esse conceito. Ele é, em todos os momentos, sujeito de sua enunciação, não se cindindo em sujeito e objeto. Com isso, Villard associa Guimarães Rosa aos muitos escritores que, no início do século XX, colocavam-se contra o corte entre narrador e narrado, que era regra entre os escritores realistas. Inversamente, ao segmentar a fala de Riobaldo em dois planos enunciativos, Lapouge-Pettorelli recorre a um expediente desses romances, que cortavam a fala das personagens do relato dos acontecimentos com o intuito de objetivar a narrativa. Com isso, Riobaldo assume o papel de narrador onisciente e, ao contar os episódios de sua vida a seu jovem interlocutor, transforma a si próprio em personagem, na não pessoa externa à situação de enunciação de que nos fala Benveniste. Ele não se faz no seu discurso, mas o precede.

O passé simple não constrói sozinho o universo autárquico de que fala Barthes. Do mesmo modo, o passé composé não é um fenômeno isolado na escrita literária moderna. O plano da enunciação da história vem acompanhado por uma lingua que se canonizou como literária, com estruturas, léxico e sintaxe que primam pela elegância e pelos ornamentos, associados à ideia de bela língua, sustentada por Vaugelas e pela academia francesa. O plano da enunciação do discurso forja-se com a chamada lingua comum ou "falada", cujos recursos serão retrabalhados de múltiplas maneiras na literatura moderna, tanto por escritores considerados regionalistas, como Charles-Ferdinand Ramuz ou Jean Giono, quanto por autores urbanos, como Ferdinand Céline ou Raymond Queneau. A revolução do romance passa pela incorporação, na literatura, do estado contemporâneo da lingua:

Trata-se de dar uma existência literária ao francês tal como se fala agora, língua absolutamente diferente do francês do século XVIII que se continua a escrever - mais ou menos mal. Digo século XVIII, pois, de fato, o francês pouco se modificou desde a época em que se tornou língua internacional (QUENEAU apud GAUVIN, 2004, p. 230, tradução nossa).

E nessa revolução está frequentemente implicada, de modo singular em cada autor, a reintrodução do sujeito na narrativa, do mesmo modo que os textos compostos na "bela lingua" implicavam, em princípio, sua exclusão.

Coerente com sua escolha pelo passé composé, Villard fará o antigo jagunço que sempre viveu no sertão exprimir-se em uma língua popular, com as marcas que lhe são próprias. No trecho que citamos, podemos observar marcas comuns de oralidade, como a supressão do ne da negação - "on était pas", "faut pas", "ils vous préviennent pas", "ma mère avait pas" -; o corte do il das frases impessoais 
- "fallait bien ruser avec ces judas", "faut pas", "y a un endroit" -; o emprego do on em vez de nous e a combinação nous, on - "nous, on s'en est retourné" -; o uso do ça- "ça faisait chagrin". Lapouge-Pettorelli, ao contrário, de modo igualmente coerente com sua opção pelo passé simple, evita essas marcas da língua falada, forjando a fala de Riobaldo em registro culto.

Do ponto de vista do léxico, a escolha por palavras "distintas" ou "sem distinção" reafirma a oposição entre as duas traduções, como se verifica nas seguintes passagens:

Ao que Diadorim me deu a mão, que malamal aceitei. E ele disse de contar. Segundo tinha procurado aqueles dias sozinho, recolhido nas brenhas, para se tratar dum ferimento, tiro que pegara na perna dele, perto do joelho, sido só de raspão. Menos entendi. A real que estando ofendido, por que era que não havia de vir para o meio da gente, para receber ajuda e ter melhor cura? Doente não foge para um recanto, no mato, solitário consigo, feito bicho faz. Aquilo podia não ser verdade? Afiguro, aí bem que criei suspeitas: aonde Diadorim não teria andado ido, e que feia ação para aprontar, com parte na fingida estória? As incertezas que tive, que não tive. Assaz ele falava assim afetuoso, tão sem outras asas; e os olhos, de ver e de mostrar, de querer bem, não consentiam de quadrar nenhum disfarce (ROSA, 2006, p. 238)

Alors Diadorim m'a tendu la main. Je l'ai prise de mauvais gré. Puis il s'est mis à tout raconter. Il avait passé ces jours seul, caché dans les brandes, soignant une blessure, une balle qu'il avait prise dans la jambe, près du genou, une simple éraflure. J'ai pas compris. J'étais vexé. Pourquoi qu'il était pas revenu parmi nous, pour qu'on l'aide et le soigne bien? Quand on est malade, on va pas se terrer seul dans un coin, comme une bête. C'était peut-être pas vrai? J'ai commencé à nourrir des soupçons, à me demander où Diadorim avait pu aller pour préparer quelque mauvais coup sous le couvert de cette histoire mensongère? Combien de doutes j'ai pu avoir et pas avoir! Pourtant il parlait si affectueusement, si naturellement, et cette grande tendresse dans ses yeux pouvait correspondre à aucune fourberie (ROSA, 1965, p. 174 - JJV).

Là-dessus, Diadorim me tendit la main, que j'acceptai à contrecoeur. Et il se mit à raconter. À l'en croire, il avait recherché ces jours solitaires, retiré au fond des bois, pour se guérir d'une blessure, un coup de feu qu'il avait pris dans la jambe, près du genou, qui n'avait fait que l'effleurer. Je compris encore moins. La réalité c'est que j'étais blessé, pourquoi est-ce qu'il n'était pas revenu comme il aurait dû parmi nous, pour recevoir de l'aide et être mieux soigné? Un malade ne se sauve pas dans un coin perdu, ou dans les bois, solitaire avec soi-même, comme font les bêtes? Ça ne pouvait pas être vrai? Je crois bien que là, j'échafaudai des soupçons: où Diadorim pouvait-il avoir couru, et dans quel mauvais dessein, pour inventer cette histoire? Les soupçons qui m'assaillirent, qui ne m'assaillirent pas. Et lui, affectueux, parlait d'abondance, tellement sans se douter de rien; et

4 A expressão é de Jérome Meizoz (2001, p. 83), ao se referir à separação entre a língua do narrador e a dos personagens, exigida pelos críticos conservadores nos anos 1920-1930. 
ses yeux, tels qu'il regardaient et signifiaient, tels qu'il aimaient, ne laissaient place à aucune feinte (ROSA, 1991, p. 256 - MLP).

Enquanto Villard busca termos simples, Lapouge-Pettorelli vale-se de termos mais nobres, que nos remetem às formulações do romantismo ou daquilo que, no imaginário comum, associa-se a ele. Assim, "malamal" torna-se "de mauvais gré" [de má vontade] no Diadorim de 1965 e "à contrecoeur" [a contragosto] no Diadorim de 1991. Do mesmo modo, "segundo tinha procurado aqueles dias sozinho" é vertido respectivamente por "il avait passé ces jours seul" [ele tinha passado aqueles dias sozinho] e "il avait recherché ces jours solitaires" [ele tinha buscado aqueles dias solitários]; "recolhido nas brenhas" por "caché dans les brandes" [escondido nos matos] e "retiré au fond des bois" [retirado no fundo dos bosques]; "sido só de raspão" por "une simple éraflure" [um simples raspão] e "qui n'avait fait que l'effleurer" [que somente o aflorara].

Nota-se também que, enquanto Villard evita a adjetivação, Lapouge-Pettorelli a busca, recorrendo frequentemente a estereótipos poéticos: "ces jours solitaires" [aqueles dias solitários], "un coin perdu" [um recanto perdido], "mauvais dessein" [mau desígnio]. Esses clichês literários têm como consequência reforçar a separação de Riobaldo com relação àquilo que conta, pois evitam que ele se coloque naquilo que diz. A lingua simples usada por Villard, mais próxima do falado, permite, ao contrário, formulações pessoalizadas. Tomemos o seguinte período da passagem aqui citada: "Segundo tinha procurado aqueles dias sozinho, recolhido nas brenhas, para se tratar dum ferimento, tiro que pegara na perna dele, perto do joelho, sido só de raspão. Menos entendi”.

Nesse trecho, ouvimos, indiretamente, a voz de Diadorim, que conta a Riobaldo o motivo de sua ausência do acampamento; mas ouvimos, também, pelo ritmo veloz das frases coordenadas por vírgulas, a desconfiança, os ciúmes de Riobaldo, que ele sintetiza na frase brevíssima: "Menos entendi".

Jean-Jacques Villard, aproximando-se da língua falada e usando o "francês elementar" (BALIBAR, 1974, p. 103-117), consegue criar a duplicidade de vozes e o ritmo veloz do primeiro período, graças ao uso de frases retas, sem ornamentos, coordenadas por vírgulas, fechadas por um singelo "j'ai pas compris". Isso faz com que o leitor francês capte a aflição de Riobaldo.

Maryvonne Lapouge-Pettorelli, ao contrário, "poetiza” o texto com vocabulário literário e adjetivações, alongando as frases e perdendo seu ritmo. A ansiedade de Riobaldo se transforma em divagação romântica. A comparação das duas traduções ressalta a natureza de cada uma delas:

\begin{tabular}{|l|l|l|}
\hline $\begin{array}{l}\text { Grande sertão: veredas } \\
\text { (ROSA, 2006) }\end{array}$ & $\begin{array}{l}\text { Diadorim } \\
\text { (ROSA, 1965, JJV) }\end{array}$ & $\begin{array}{l}\text { Diadorim } \\
\text { (ROSA, 1991, MLP) }\end{array}$ \\
\hline $\begin{array}{l}\text { Segundo tinha procurado } \\
\text { aqueles dias sozinho, }\end{array}$ & $\begin{array}{l}\text { Il avait passé ces jours } \\
\text { seul, }\end{array}$ & $\begin{array}{l}\text { À l'en croire, il avait } \\
\text { recherché ces jours } \\
\text { solitaires, }\end{array}$ \\
\hline recolhido nas brenhas, & caché dans les brandes, & retiré au fond des bois, \\
\hline
\end{tabular}


(continuação)

\begin{tabular}{|l|l|l|}
\hline $\begin{array}{l}\text { Grande sertão: veredas } \\
\text { (ROSA, 2006) }\end{array}$ & $\begin{array}{l}\text { Diadorim } \\
\text { (ROSA, 1965, JJV) } \\
\text { para se tratar de um } \\
\text { ferimento, }\end{array}$ & $\begin{array}{l}\text { Diadorim } \\
\text { (ROSA, 1991, MLP) }\end{array}$ \\
\hline $\begin{array}{l}\text { tiro que pegara na perna } \\
\text { dele, }\end{array}$ & $\begin{array}{l}\text { une balle qu'il avait prise } \\
\text { dans la jambe, }\end{array}$ & $\begin{array}{l}\text { un coup de feu qu'il avait } \\
\text { pris dans la jambe, } \\
\text { blessure, }\end{array}$ \\
\hline perto do joelho, d'une \\
\hline sido só de raspão. & près du genou, & près du genou, \\
\hline Menos entendi. & une simple éraflure. & $\begin{array}{l}\text { qui n'avait fait que } \\
\text { l'effleurer }\end{array}$ \\
\hline
\end{tabular}

As perguntas que seguem manifestam ainda mais o tormento de Riobaldo:

A real que estando ofendido, por que era que não havia de vir para o meio da gente, para receber ajuda e ter melhor cura? Doente não foge para um recanto, ou mato, solitário consigo, feito bicho faz. Aquilo podia não ser verdade? Afiguro, aí bem que criei suspeitas: aonde Diadorim não teria andado ido, $e$ que feia ação para aprontar, com parte na fingida estória? As incertezas que tive, que não tive.

Elas podem ser interpretadas como dirigidas simultaneamente a três destinatários: a Diadorim, que Riobaldo questiona silenciosamente, ao próprio Riobaldo, que se pergunta o que o amigo teria feito, se estaria mentindo, e ao interlocutor de Riobaldo, a quem ele conta a história. Essa confusão de destinatários faz com que a fronteira passado e presente se rompa: a angústia antiga se refaz no presente da enunciação. Guimarães Rosa consegue esse efeito usando interrogações enfáticas coloquiais "por que era que", "aonde Diadorim não teria andado ido", uma reprimenda "doente não foge para um recanto...", uma interrogação que escancara a sua dúvida "aquilo podia não ser verdade?” e, finalmente, como no período anterior, com uma frase lapidar, que resume os seus sentimentos ambíguos: "as incertezas que tive, que não tive".

Jean-Jacques Villard consegue reproduzir essa confusão de vozes ao usar, novamente, o francês coloquial, desobedecendo as regras sintáticas da gramática normativa - "pourquoi qu'il était pas revenu parmi nous [...]" - ou mantendo a ordem direta das interrogações - "où Diadorim avait pu aller [..." - e, sobretudo, produzindo frases que podem ser oralizadas, ou seja, nas quais se podem ouvir suas perguntas silenciosas dirigidas a Diadorim. O emprego do pronome "on" contribui para essa oralização e para que as pessoas envolvidas na interrogação sejam múltiplas: "Pourquoi qu'il était pas revenu parmi nous, pour qu'on l'aide et le soigne bien? Quand on est malade, on va pas se terrer seul dans un coin, comme une bête".

Maryvonne Lapouge-Pettorelli, mais uma vez no movimento inverso, usa interrogativas com inversão do sujeito e do verbo - "où Diadorim pouvait-il avoir couru [...]" - e fórmulas de terceira pessoa - "pourquoi est-ce qu'il n'était pas re- 
venu comme il aurait dû parmi nous, pour recevoir de l'aide et être mieux soigné? Un malade ne se sauve pas dans un coin perdu, ou dans les bois, solitaire avec soi-même, comme font les bêtes?". Isso reduz a multiplicidade de vozes que existe no texto rosiano e, consequentemente, sua pessoalidade.

A transformação dessa última pergunta para o discurso direto, como se ela se dirigisse diretamente a Diadorim, pode nos dar uma dimensão mais precisa do efeito das duas traduções. A de Lapouge-Pettorelli se aproximaria do teatro clássico: "Por que não terias voltado entre nós, como deverias, para receberes ajuda e teres melhores cuidados? Um doente não foge para um recanto perdido, ou para os bosques, solitário consigo mesmo, como fazem os bichos". Ao passo que a de Villard se mostra mais coloquial: "Por que você não voltou para o meio de nós, para a gente te ajudar e cuidar de você? Quando a gente está doente, a gente não vai se enfiar sozinho num canto, como um bicho". Podemos notar que, na retrotradução, o léxico e a sintaxe de Maryvonne, que conferem um tom clássico ao texto, nos fizeram escolher o "tu" como pronome de tratamento, assim como os de Villard, mais coloquiais, nos fizeram escolher "você".

Uma última consideração. O fechamento desse período "as incertezas que tive, que não tive", que marca os sentimentos dúbios de Riobaldo em frases breves e diretas, é vertida por Villard também de forma breve, com palavras da língua corrente "Combien de doutes j'ai pu avoir et pas avoir!" [quantas dúvidas pude ter e não ter], enquanto Maryvonne elabora uma frase longa, com palavras mais "literárias", "Les soupçons qui m'assaillirent, qui ne m'assaillirent pas" [as dúvidas que me assaltaram, que não me assaltaram], o que lhe confere uma dramaticidade quase cômica.

\section{Conclusão}

Os tradutores de Guimarães Rosa expressam, em geral, o desejo de resgatar a poesia de sua obra. Jean-Jacques Villard, em sua correspondência com o escritor, afirma-1he que "para traduzi-lo, é preciso antes de tudo se ater ao espírito, depois, tentar encontrar a forma que se adapte ao espírito, mas nunca se ater unicamente à forma" (Carta de Jean-Jacques Villard a Guimarães Rosa, 12.11.1963 in ROSA, [1961-1967]). Maryvonne Lapouge-Pettorelli (1991, p. 17), por sua vez, em nota à sua tradução de Grande sertão: veredas, diz que, para João Guimarães Rosa, "as dimensões poética e mítica deveriam, no espírito dos tradutores, e dos leitores futuros, sempre primar sobre a imediata realidade". O modo como cada tradutor concebe essa poética pode contudo ser bastante diverso, e se manifestará na maneira como compõe o seu texto.

Grande sertão: veredas se caracteriza, como verificamos sucintamente no início deste artigo, pela unidade de interno e externo, de modo que tanto a realidade aparentemente mais referencial quanto o próprio sujeito são constituídos no contar de Riobaldo Tatarana. Maryvonne Lapouge-Pettorelli, cindindo a narrativa em dois planos de enunciação e transformando Riobaldo Tatarana em narrador onisciente de sua própria história, mostra que o seu conceito de literário liga-se à tipologia estabelecida pelos romances do século XIX que se transformaram, junto com as imagens do romantismo, em estereótipos escolares de poesia. Com isso, ela retira do romance sua característica 
maior, transformando o contar de Riobaldo em lembranças de velhos, justamente o que não queria Guimarães Rosa.

Ao contrário, compondo a narração de Riobaldo no plano da enunciação do discurso e na "bela linguagem chamada de corrente" (LEFRÈVE, 1961), Jean-Jacques Villard alinha-se, embora de modo menos elaborado, com as vanguardas literárias de sua época que pretendiam renovar a literatura apoiando-se nos recursos da lingua falada. Com isso, ele cria um texto que recupera, embora de modo menos sutil que Guimarães Rosa, a subjetividade fundamental da prosa desse escritor, conferindo à voz de Riobaldo, para citar novamente a expressão de Barthes, "a espessura da existência".

\section{The translation of SubJectivity in the two French translations of Grande SERTÃO: VEREDAS}

Abstract: Grande sertão: veredas was translated into French for the first time in the middle of the 1960s, and it received a second translation in the beginning of the 1990s. The aim of this paper is to identify how each one of the translators perceives the singularity of Guimarães Rosa's writing through the resumption of the translation projects conducted by each one of them.

Keywords: Translation. Subjectivity. Grande sertão: veredas.

\section{REFERÊNCIAS}

BALIBAR, R. Les français fictifs: le rapport des styles littéraires au français national. Paris: Hachette, 1974.

BANDEIRA, M. Grande sertão: veredas. In: BANDEIRA, M. Poesia completa e prosa. 2. ed. Rio de Janeiro: Aguillar, 1967. p. 590-592.

BARTHES, R. O rumor da língua. Tradução Mário Laranjeira. São Paulo: Martins Fontes, 2004.

BENVENISTE, É. Problemas de lingüistica geral I. Tradução Maria da Glória Novak e Maria Luisa Neri. Revisão Isaac N. Salum. Campinas: Pontes, 1995.

BERMAN, A. A tradução e a letra ou o albergue do longínquo. Tradução Mauri Furlan, Marie-Hélène Catherine Torres e Andréia Guerini. Rio de Janeiro: 7Letras/PGET, 2007.

CAMPOS, A. de. Um lance de "dês" do Grande Sertão. In: XISTO, P.; CAMPOS, A. de; CAMPOS, H. de. Guimarães Rosa em três dimensões. São Paulo: Conselho Estadual de Cultura, Comissão de Literatura, 1970.

CANDIDO, A. O homem dos avessos. In: COUTINHO, E. F. de (Org.). Guimarães Rosa. Rio de Janeiro: Civilização Brasileira, 1983. (Coleção Fortuna Crítica, p. 294-309).

GAUVIN, L. La fabrique de la langue: de François Rabelais à Réjean Ducharme. Paris: Seuil, 2004. 
LAPOUGE-PETTORELLI, M. Note du traducteur. In: ROSA, J. G. Diadorim. Tradução Maryvonne Lapouge-Pettorelli. Paris: Albin Michel, 1991. p. 16.

LARANJEIRA, M. Poética da tradução. São Paulo: Edusp, 1993.

LEFRÈVE, R. Buriti. Le Canard Enchaîné, Paris, 3 mars 1961. Lettres ou pas lettres. Fundo Guimarães Rosa, Instituto de Estudos Brasileiros, Universidade de São Paulo. Recorte de jornal.

MEIZOZ, J. L'âge du roman parlant (1919-1939): écrivains, critiques, linguistes et pédagogues en débat. Genève: Droz, 2001.

MESCHONNIC, H. Critique du rythme: anthropologie historique du langage. 2. ed. Verdier, 1982.

PROENÇA, M. C. Trilhas no Grande sertão. Rio de Janeiro: Ministério da Educação e Cultura, Serviço de Documentação, 1958.

ROSA, J. G. Correspondência com seu tradutor francês, Jean-Jacques Villard. Fundo Guimarães Rosa do Instituto de Estudos Brasileiros (IEB), da Universidade de São Paulo, [1961-1967].

ROSA, J. G. Correspondência com seu tradutor espanhol, Ángel Crespo. Fundo Guimarães Rosa do Instituto de Estudos Brasileiros (IEB), da Universidade de São Paulo, [1964-1967].

ROSA, J. G. Diadorim. Tradução Jean-Jacques Villard. Paris: Albin Michel, 1965.

ROSA, J. G. Correspondência com seu tradutor italiano, Edoardo Bizzarri. São Paulo: Queiroz; Instituto Cultural Ítalo-Brasileiro, 1981.

ROSA, J. G. Diadorim. Tradução Maryvonne Lapouge-Pettorelli. Paris: Albin Michel, 1991.

ROSA, J. G. Diálogo com Guimarães Rosa. In: COUTINHO, E. F. de (Org.). Guimarães Rosa. Rio de Janeiro: Civilização Brasileira, 1983. (Coleção Fortuna Crítica, p. 62-97).

ROSA, J. G. Correspondência com seu tradutor alemão, Curt Meyer-Clason. Edição, organização e notas: Maria Apparecida F. M. Bussolotti. Tradução das cartas em alemão: Erlon José Pascal. Rio de Janeiro: Nova Fronteira; Academia Brasileira de Letras; Belo Horizonte: UFMG, 2003.

ROSA, J. G. Grande sertão: veredas. Rio de Janeiro: Nova Fronteira, 2006. (Coleção Biblioteca do Estudante).

STENDHAL. O vermelho e o negro. São Paulo: Abril Cultural, 1979.

UTÉZA, F. A metafísica roseana em tradução. Revista Escritural, n. 8, fev. 2015. Disponivel em: <http://www.mshs.univ-poitiers.fr/crla/contenidos/ESCRITURAL/ESCRITURAL8/ESCRITURAL_8_SITIO/PAGES/D18_Entrevista.html> . Acesso em: 14 nov. 2017.

UTÉZA, F. JGR Metafísica do grande sertão. São Paulo: Edusp, 2016.

VERLANGIERI, I. V. R. J. Guimarães Rosa: correspondência inédita com a tradutora norte-americana Harriet de Onís. 1993. 359 f. Dissertação (Mestrado em Estudos Literários)-Faculdade de Ciências e Letras, Universidade Estadual Paulista "Júlio de Mesquita Filho", Araraquara, 1993.

VILLARD, J.-J. Note du traducteur. In: ROSA, J. G. Diadorim. Tradução Jean-Jacques Villard. Paris: Albin Michel, 1965. p. 9. 
DOSSIÊ

WARD, T. S. O discurso oral em Grande sertão: veredas. São Paulo: Duas Cidades; Brasília: INL; Fundação Pró-Memória, 1984.

Recebido em setembro de 2017.

Aprovado em setembro de 2017. 